\title{
In Vitro Biofilm Activity of Non-Candida albicans Candida Species
}

\author{
Sónia Silva $\cdot$ Mariana Henriques $\cdot$ Rosário Oliveira $\cdot$ \\ David Williams $\cdot$ Joana Azeredo
}

Received: 1 December 2009/Accepted: 6 April 2010/Published online: 17 April 2010

(C) Springer Science+Business Media, LLC 2010

\begin{abstract}
Candidosis has been attributed to C. albicans; however, infections caused by non-Candida albicans Candida (NCAC) species are increasingly being recognised. The ability of Candida to grow as a biofilm is an important feature that promotes both infection and persistence in the host. The biofilms' activity is significant since high activity might be associated with enhanced expression of putative virulence factors, whilst in contrast low activity has previously been suggested as a mechanism for resistance of biofilm cells to antimicrobials. The aim of this study was to determine the metabolic activity of in vitro biofilms formed by different clinical isolates of NCAC species. The in situ total metabolic activity of $C$. parapsilosis, C. tropicalis and C. glabrata biofilms was determined using 2,3-(2-methoxy-4-nitro-5sulphophenyl)-5-[(phenylamino) carbonyl]-2H-tetrazolium hydroxide (XTT) reduction assay, and the number of cultivable cells was also established by CFU (colony forming unit) counts. The biofilm structure was assessed by scanning electron microscopy (SEM). Results showed that total biofilm metabolic activity was species and strain dependent. C. glabrata exhibited the lowest biofilm metabolic activity despite having the highest number of biofilm cultivable cells. Similarly, the metabolic activity of resuspended C. glabrata biofilm and planktonic cells was lower than that of the other species. This study demonstrates the existence of intrinsic activity differences amongst NCAC species, which could have important implications in terms of species relative
\end{abstract}

S. Silva $\cdot$ M. Henriques $(\bowtie) \cdot$ R. Oliveira $\cdot$ J. Azeredo Institute for Biotechnology and Bioengineering, Universidade do Minho, Campus de Gualtar, 4710-057 Braga, Portugal

e-mail: mcrh@deb.uminho.pt

D. Williams

School of Dentistry, Cardiff University, Heath Park,

Cardiff CF14 4XY, UK virulence. Furthermore, the absence of an obvious correlation, between cultivable cells number and total biofilm activity, raises the question about which parameter is the most appropriate for the in vitro assessment of biofilms and their potential clinical significance.

\section{Introduction}

Candidosis is the most prevalent opportunistic fungal infection of humans and of particular significance into patients undergoing treatment for cancer [17], organ transplantation [10] and receiving broad-spectrum antibiotics [26]. Candidosis is also one of the most common and persistent infections in HIV-infected individuals and AIDS patients [27].

Amongst Candida species, Candida albicans is the most commonly isolated and responsible for the majority of superficial and systemic infections [23]. However, many non-Candida albicans Candida (NCAC) species, such as Candida glabrata, Candida parapsilosis and Candida tropicalis have recently emerged as important pathogens in suitably debilitated individuals. This fact is highlighted by recent epidemiology studies reporting that NCAC are currently estimated to be responsible for approximately $60 \%$ of fungemia $[4,6]$.

A major virulence factor of Candida is its ability to adapt to a variety of different habitats and the consequent formation of surface-attached microbial communities known as biofilms [7, 8]. Candida biofilms can develop on natural host surfaces or on biomaterials used in indwelling medical devices. Importantly, such biofilms are phenotypically distinct from their 'free-living' or planktonic forms, with biofilms exhibiting elevated resistance to host defences and administered antimicrobial agents $[3,11,27]$. The clinical 
significance of biofilms is highlighted by recent estimates that over $65 \%$ of all hospital infections originate from these microbial communities [21]. As a consequence researchers are now recognising the importance of studying biofilm communities rather than planktonic forms when characterising the pathogenic potential of microorganisms. So far, a variety of methods have been described for both the in vitro production of biofilms and their subsequent characterisation. Indirect methods based on 96-well microtiter plate assays, which allow the simultaneous quantification of yeasts in a large number of biofilm samples, have been recommended due to their simplicity and sensitivity [13, 18]. A frequently used approach to quantify biofilm cells activity has been the reduction assay of the tetrazolium salt 2,3-(2-methoxy-4-nitro-5-sulphophenyl)-5-[(phenylamino) carbonyl]-2H-tetrazolium hydroxide (XTT). In this colorimetric method, XTT is reduced to an XTT formazan product by mitochondrial dehydrogenases of metabolically active cells. The resulting colorimetric changes are considered to be proportional to the number of living cells and their metabolic activity $[13,18]$.

Previous Candida biofilm studies have been mainly focussed on $C$. albicans biofilms [2, 5, 13, 15, 16], with very few examining NCAC species [1, 12, 28]. Furthermore, the vast majority of candidal biofilm research has been focussed on the assessment of biofilm development either by biomass determination or by quantifying the number of cells in the biofilm. The activity of the biofilm itself or its cellular composition has rarely been investigated [18]. This oversight is important given the fact that biofilm activity has significance in terms of pathogenicity as it is a likely indicator of growth, production of hydrolytic enzymes and, in the case of reduced activity, of possible resistance to antimicrobial activity. Therefore, considering that the biofilm activity is a requirement in Candida infections, the aim of this study was to determine the metabolic activity of in vitro biofilms formed by different clinical isolates of NCAC species.

\section{Materials and Methods}

\section{Organisms and Growth Conditions}

A total of 18 clinical strains (Table 1) of $C$. parapsilosis $(n=6), C$. tropicalis $(n=6)$ and $C$. glabrata $(n=6)$ that had previously been recovered from oral, vaginal or urinary tract infections were used in this study. Strains isolated from vaginal and urinary tract infections were kindly provided by the Hospital of São Marcos (Braga, Portugal). Candida tropicalis strains 12 and 75 (recovered from the vaginal tract) were provided by the University of Maringá (Maringá, Brazil). Oral isolates were originally isolated from patients attending the Clínica dos Congregados (Braga, Portugal). Three reference strains, namely $C$. parapsilosis (ATCC 22019), C. tropicalis (ATCC 750) and C. glabrata (ATCC 2001) were also included in this study. The identity of all isolates was confirmed using CHROMagar ${ }^{\circledR}$ Candida (CHROMagar, Paris, France) and by PCR sequencing using specific primers (ITS1 and ITS4) targeting the 5.8S ribosomal RNA subunit gene [29].

Before the experiments, all isolates were cultured on Sabouraud Dextrose Agar (SDA; Merck, Germany) for $48 \mathrm{~h}$ at $37^{\circ} \mathrm{C}$. Cells were then subcultured in Sabouraud Dextrose Broth (SDB; Merck, Germany) for $18 \mathrm{~h}$ at $37^{\circ} \mathrm{C}$ in an orbital shaker (120 rev/min). Cells were then harvested by centrifugation at $3000 \times g$ for $10 \mathrm{~min}$ at $4^{\circ} \mathrm{C}$ and washed twice in phosphate buffer saline (PBS $\mathrm{pH} 7$, $0.1 \mathrm{M})$. The cell pellets were finally resuspended in SDB, and the cell concentration was adjusted using an improved Neubauer haemocytometer to a standardised level $\left(1 \times 10^{7}\right.$ or $1 \times 10^{8}$ cells $\left./ \mathrm{ml}\right)$ depending on the experiment.

\section{Biofilm Formation}

Biofilms were produced in 96-well microtiter plates (Orange Scientific, Braine-l' Alleud, Belgium). Briefly, standardised inocula (200 $\mu$ l of yeast cell suspension containing $1 \times 10^{7}$ cells $/ \mathrm{ml}$ in SDB) were placed into selected wells and incubated at $37^{\circ} \mathrm{C}$ in an orbital shaker incubator at $120 \mathrm{rev} / \mathrm{min}$. After $24 \mathrm{~h}$, an aliquot of $100 \mu \mathrm{l}$ of SDB medium was removed and an equal volume of fresh SDB added. The microtiter plates were then incubated for further $48 \mathrm{~h}$. Experiments were performed in triplicate and on at least three separate occasions.

\section{Biofilm Characterisation}

\section{In Situ Biofilm Metabolic Activity}

An XTT reduction assay [13, 14] was used to determine the in situ biofilm metabolic activity of the NCAC strains. After biofilm formation, the culture medium was aspirated and the non-adherent cells were removed by washing the biofilms twice in PBS. A $200 \mu$ aliquot of a solution containing $100 \mu \mathrm{g} / \mu \mathrm{l}$ of XTT (2,3-(2-methoxy-4-nitro-5sulphophenyl)-5-[(phenylamino) carbonyl]-2H-tetrazolium hydroxide) (Sigma-Aldrich, USA) and $10 \mu \mathrm{g} / \mu \mathrm{l}$ of phenazine methosulphate (PMS) (Sigma-Aldrich, USA) was then added to each pre-washed biofilm and also to the control wells (to measure background XTT levels). The plates were then incubated for $3 \mathrm{~h}$ in the dark, at $37^{\circ} \mathrm{C}$ with agitation (120 rev/min). Colorimetric changes were measured at $490 \mathrm{~nm}$ using a microtiter plate reader $\left(\right.$ Bio-Tek $^{\circledR}$ Synergy HT, Izasa, Portugal) and the absorbance values were standardised per unit area of well (absorbance $/ \mathrm{cm}^{2}$ ). 
Table 1 Non-Candida albicans Candida strains used in this study, values of in situ total biofilm activity, relative biofilm activity and metabolic activity of biofilm and planktonic cells

\begin{tabular}{|c|c|c|c|c|c|c|}
\hline \multirow[t]{2}{*}{ Species } & \multirow[t]{2}{*}{ Strains } & \multirow[t]{2}{*}{ Origin } & \multirow{2}{*}{$\begin{array}{l}\text { In situ total } \\
\text { biofilm activity } \\
\text { (Abs values } / \mathrm{cm}^{2} \text { ) } \\
\pm \mathrm{SD}\end{array}$} & \multirow{2}{*}{$\begin{array}{l}\text { Relative } \\
\text { biofilm activity } \\
\text { (Abs values/ } \\
10^{8} \mathrm{CFU} \text { ) }\end{array}$} & \multicolumn{2}{|c|}{$\begin{array}{l}\text { Cellular metabolic activity } \\
\text { (Abs values } / 10^{8} \text { cells) } \pm \mathrm{SD}\end{array}$} \\
\hline & & & & & Biofilm cells & Planktonic cells \\
\hline \multirow[t]{7}{*}{ C. parapsilosis } & 534638 & Urinary tract & $0.198 \pm 0.01$ & 0.518 & $0.548 \pm 0.08$ & $0.621 \pm 0.05$ \\
\hline & 553877 & & $0.099 \pm 0.04$ & 0.199 & $0.323 \pm 0.04$ & $0.474 \pm 0.13$ \\
\hline & $\mathrm{AD}$ & Oral tract & $0.297 \pm 0.07$ & 0.055 & $0.387 \pm 0.06$ & $0.702 \pm 0.19$ \\
\hline & AM2 & & $0.337 \pm 0.13$ & 0.116 & $0.587 \pm 0.09$ & $0.407 \pm 0.09$ \\
\hline & 491861 & Vaginal & $0.405 \pm 0.02$ & 1.311 & $0.534 \pm 0.11$ & $0.554 \pm 0.11$ \\
\hline & 513143 & & $0.537 \pm 0.04$ & 1.677 & $0.496 \pm 0.11$ & $0.669 \pm 0.11$ \\
\hline & ATCC 22019 & Reference & $0.454 \pm 0.09$ & 1.134 & $0.221 \pm 0.05$ & $0.492 \pm 0.05$ \\
\hline \multirow[t]{7}{*}{ C. tropicalis } & 519468 & Urinary tract & $0.115 \pm 0.03$ & 0.295 & $0.273 \pm 0.01$ & $0.702 \pm 0.15$ \\
\hline & 544123 & & $0.179 \pm 0.02$ & 1.059 & $0.283 \pm 0.07$ & $0.867 \pm 0.07$ \\
\hline & AG1 & Oral tract & $0.322 \pm 0.05$ & 1.094 & $0.345 \pm 0.07$ & $0.467 \pm 0.04$ \\
\hline & $\mathrm{T} 2.2$ & & $0.259 \pm 0.02$ & 0.922 & $0.162 \pm 0.02$ & $0.585 \pm 0.09$ \\
\hline & 12 & Vaginal & $0.185 \pm 0.01$ & 0.041 & $0.313 \pm 0.02$ & $0.298 \pm 0.01$ \\
\hline & 75 & & $0.137 \pm 0.03$ & 3.672 & $0.376 \pm 0.07$ & $0.323 \pm 0.01$ \\
\hline & ATCC 750 & Reference & $0.507 \pm 0.09$ & 16.80 & $0.665 \pm 0.11$ & $0.688 \pm 0.02$ \\
\hline \multirow[t]{7}{*}{ C. glabrata } & 562123 & Urinary tract & $0.223 \pm 0.04$ & 0.006 & $0.228 \pm 0.07$ & $0.281 \pm 0.09$ \\
\hline & 513100 & & $0.129 \pm 0.03$ & 0.002 & $0.100 \pm 0.02$ & $0.149 \pm 0.01$ \\
\hline & D1 & Oral tract & $0.237 \pm 0.09$ & 0.006 & $0.179 \pm 0.03$ & $0.138 \pm 0.07$ \\
\hline & AE2 & & $0.201 \pm 0.08$ & 0.052 & $0.167 \pm 0.02$ & $0.135 \pm 0.04$ \\
\hline & 534784 & Vaginal & $0.172 \pm 0.07$ & 0.049 & $0.131 \pm 0.03$ & $0.079 \pm 0.03$ \\
\hline & 585626 & & $0.118 \pm 0.05$ & 0.031 & $0.084 \pm 0.02$ & $0.201 \pm 0.06$ \\
\hline & ATCC 2001 & Reference & $0.238 \pm 0.06$ & 0.084 & $0.181 \pm 0.05$ & $0.732 \pm 0.14$ \\
\hline
\end{tabular}

$S D$ standard deviation

\section{Quantification of Biofilm Cultivable Cells}

The number of cultivable biofilm cells was determined by counting colony forming units (CFUs) following biofilm cells resuspension. Briefly, biofilms were first washed twice in PBS to remove loosely attached cells and the biofilm was then resuspended by repeated pipetting. Complete removal of the biofilm was confirmed by subsequent crystal violet staining and spectrophotometric reading for inspection of the wells. The resuspended biofilm $(500 \mu \mathrm{l})$ was vigorously vortexed for $5 \mathrm{~min}$ to disrupt the biofilm matrix and serial decimal dilutions (in PBS) were plated onto SDA. Agar plates were incubated for $24 \mathrm{~h}$ at $37^{\circ} \mathrm{C}$, and the total CFUs per unit area $\left(\mathrm{Log} \mathrm{CFU} / \mathrm{cm}^{2}\right)$ of microtiter plate well were enumerated. Experiments were repeated on three occasions with individual samples evaluated in triplicate.

\section{Biofilm Structure}

Biofilm structure was examined by Scanning Electron Microscopy (SEM). Biofilms were formed by seeding $2 \mathrm{ml}$ of the standardised cell suspension $\left(1 \times 10^{7}\right.$ cells $/ \mathrm{ml}$ in
SDB) into 24-well plates (Orange Scientific, Braine-1'Alleud, Belgium) and incubated for $48 \mathrm{~h}$ at $37^{\circ} \mathrm{C}$ and $120 \mathrm{rev} /$ min. After $24 \mathrm{~h}, 1 \mathrm{ml}$ of SDB medium was removed and an equal volume of fresh SDB added. At $48 \mathrm{~h}$, the medium was aspirated and non-adherent cells removed by washing the biofilms twice with sterile ultra-pure water. Samples were dehydrated with alcohol (using 70\% ethanol for $10 \mathrm{~min}$, 95\% ethanol for $10 \mathrm{~min}$ and $100 \%$ ethanol for $20 \mathrm{~min}$ ) and air dried for $20 \mathrm{~min}$. Samples were kept in a desiccator until the base of the wells was removed for analysis. Prior to observation, the base of the wells was mounted onto aluminium stubs, sputter-coated with gold and observed with an S-360 scanning electron microscope (Leo, Cambridge, USA).

\section{Quantification of Cellular Metabolic Activity}

\section{Metabolic Activity of Biofilms Cells}

Biofilms were removed from the microtiter plate wells as described previously and the cell concentration adjusted to $1 \times 10^{8}$ cells $/ \mathrm{ml}$ using an improved Neubauer 
haemocytometer. Cells from $1 \mathrm{ml}$ of the standardised cell preparation were harvested by centrifugation $(3000 \times g)$, and the supernatant was discarded. An aliquot of $1 \mathrm{ml}$ of XTT solution $(100 \mu \mathrm{g} / \mu \mathrm{l}$ of XTT and $10 \mu \mathrm{g} / \mu \mathrm{l}$ of PMS) was added to the yeast cells pellet. The mixture was then incubated in the dark for $3 \mathrm{~h}$ at $37^{\circ} \mathrm{C}$ and $120 \mathrm{rev} / \mathrm{min}$. Colorimetric changes were measured as previously described and activity expressed as absorbance $/ 1 \times 10^{8}$ cells. Experiments were repeated on three occasions with individual samples evaluated in triplicate.

\section{Metabolic Activity of Planktonic Cells}

Cells were inoculated in SDB for $18 \mathrm{~h}$ at $37^{\circ} \mathrm{C}$ under agitation $(120 \mathrm{rev} / \mathrm{min})$ and then harvested by centrifugation $\left(3000 \times g\right.$ for $10 \mathrm{~min}$ at $\left.4^{\circ} \mathrm{C}\right)$ and washed twice in PBS. After resuspension in PBS, the cell concentration was adjusted to $1 \times 10^{8}$ cells $/ \mathrm{ml}$ and the cellular metabolic activity was measured as previously described for the resuspended biofilm cells.

\section{Statistical Analysis}

Results were compared using a one-way analysis of variance (ANOVA) by applying Levene's test of homogeneity of variance and the Tukey multiple-comparisons test, using SPSS software (SPSS [Statistical Package for the Social Sciences], Inc., Chicago, IL). All tests were performed with a confidence level of $95 \%$.

\section{Results and Discussion}

The primary aim of this study was to determine the total in situ biofilm activity of 21 strains of NCAC species using an XTT reduction assay (Fig. 1). It was clearly evident that biofilm metabolic activity was species and strain dependent. Specifically, the overall mean metabolic activity of C. glabrata $\left(\mathrm{Abs} / \mathrm{cm}^{2}=0.19 \pm 0.05\right)$ biofilms was lower than for $C$. parapsilosis $\left(\mathrm{Abs} / \mathrm{cm}^{2}=0.33 \pm 0.15\right)$ and C. tropicalis $\left(\mathrm{Abs} / \mathrm{cm}^{2}=0.24 \pm 0.14\right)$. Such intra species variation in terms of biofilm formation has previously been demonstrated albeit using parameters other than activity $[12,28]$. It was interesting to note that in the case of C. parapsilosis, both urinary tract isolates $(534638$ and 553877) had significantly $(P<0.05)$ lower biofilm metabolic activity $\left(\mathrm{Abs} / \mathrm{cm}^{2}=0.20 \pm 0.01 ; \quad 0.09 \pm 0.04\right)$ compared with the other $C$. parapsilosis strains. Whether this finding relates to an inherent difference between strains from distinct pathological origins is unclear, and further investigation involving larger number of strains from these conditions is needed to clarify this point.

There are several possible reasons for the observed species and strain differences in in situ biofilm metabolic activity. A key factor would obviously be the relative number of metabolic active cells within the biofilm itself. In order to analyse this, CFU counts for each biofilm were determined. In contrast to what would perhaps be expected, there was no correlation between biofilm metabolic activity (Fig. 1) and CFU number (Fig. 2). It was evident that despite $C$. glabrata biofilms having the lowest metabolic activity, these biofilms had significantly $(P>0.05)$ higher number of cultivable cells per unit area (Log CFU/ $\left.\mathrm{cm}^{2}=9.16 \pm 0.59\right)$ when compared with $C$. tropicalis $\left(\log \mathrm{CFU} / \mathrm{cm}^{2}=7.34 \pm 0.72\right)$ and C. parapsilosis ( $\mathrm{Log}$ $\mathrm{CFU} / \mathrm{cm}^{2}=7.82 \pm 0.09$ ). Furthermore, also the intrastrain variation observed for $C$. parapsilosis and C. tropicalis in terms of biofilm metabolic activity (Fig. 1) was not associated with differences in CFU numbers (Fig. 2). The observed discrepancy between in situ total biofilm activity and the number of cultivable cells does have important implications for biofilm studies, since it is often assumed
Fig. 1 Absorbance values of XTT solutions per $\mathrm{cm}^{2}$ of biofilms formed in SDB for $48 \mathrm{~h}$ by different clinical isolates of C. parapsilosis, C. tropicalis and C. glabrata. Error bars represent standard deviation. * Strains of the same species that are significantly different $(P<0.05)$

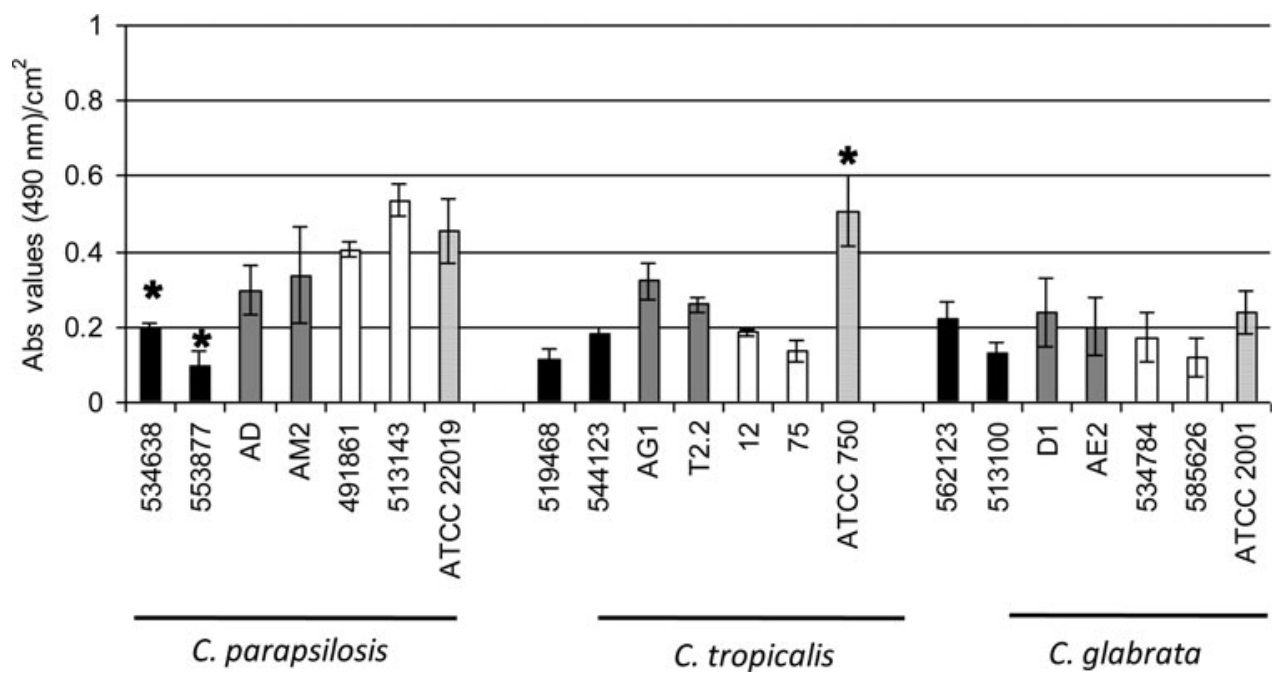


Fig. 2 Logarithm of number cells of C. parapsilosis, C. tropicalis and C. glabrata per $\mathrm{cm}^{2}$ of the biofilm formed in SDB after 48 h. Error bars represent standard deviation. * Strains of the same species that are significantly different $(P<0.05)$

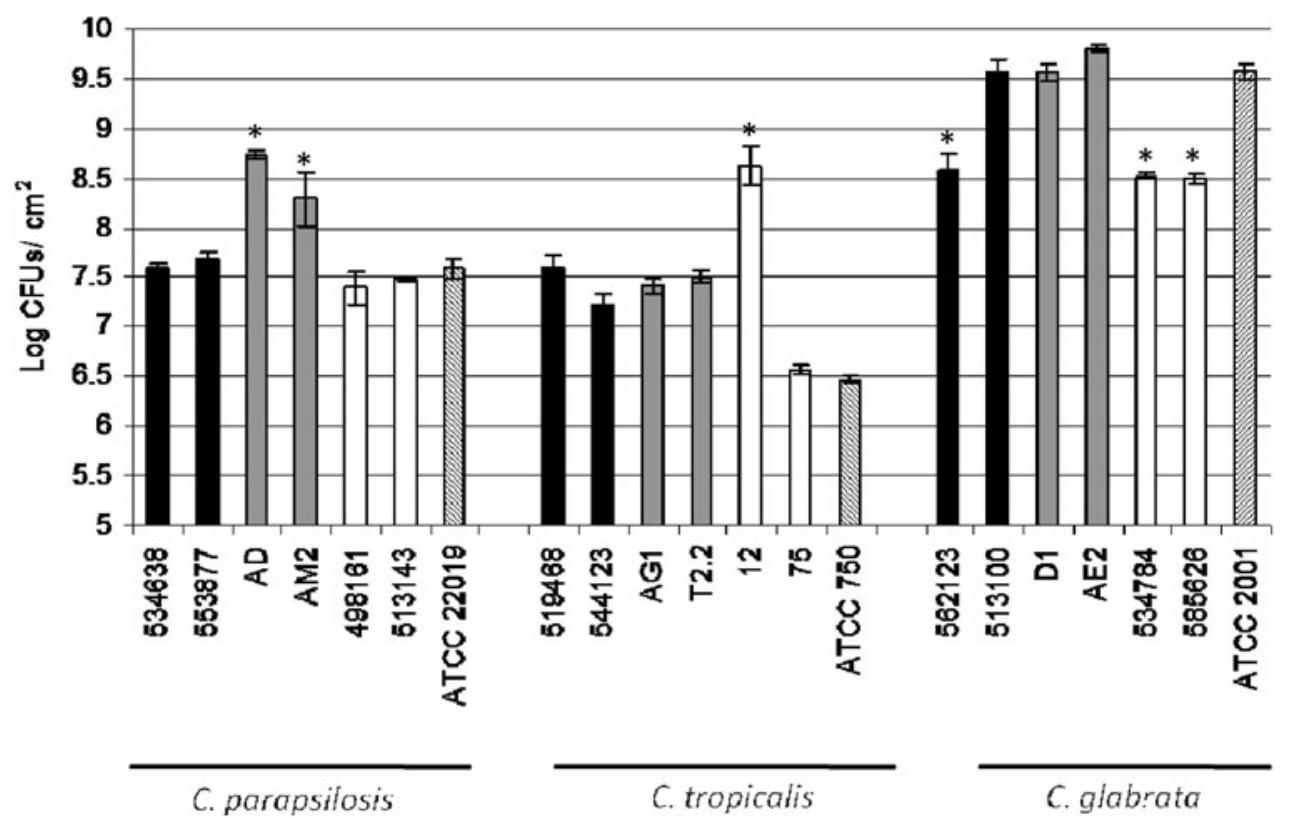

that metabolic activity measurements provide a sufficient correlation to indirectly quantify biofilms [5, 13, 30]. This situation may be adequate when comparing a single strain type under different environmental conditions but is problematic when multiple strains and species are being compared [19].

In terms of species and strain differences, consideration has to be given to inherent differences in the relative size, morphology and biochemistry of cells. It is known that C. glabrata cells are generally smaller $(1-4 \mu \mathrm{m})$ than C. tropicalis $(4-8 \mu \mathrm{m})$ and $C$. parapsilosis $(2.5-4 \mu \mathrm{m})$ [24] and also have a narrower spectrum of carbohydrate utilisation [9, 20]. Unlike C. parapsilosis and C. tropicalis, C. glabrata (Fig. 3) is unable to generate filamentous forms which may also be expected to exhibit different metabolic activity, and thus contribute to species differences [18]. Inherent species differences would be supported by the control experiments (Table 1) where planktonic cultures illustrated similar differences between the species with C. glabrata again having lower cellular metabolic activity compared with the other two species. Specifically, it was shown that $C$. glabrata biofilm cells had, on average, a lower metabolic activity $\left(\mathrm{Abs} / 1 \times 10^{8}\right.$ cells $\left.=0.15 \pm 0.03\right)$ than either $C$. tropicalis $\left(\mathrm{Abs} / 1 \times 10^{8}\right.$ cells $\left.=0.35 \pm 0.16\right)$ or C. parapsilosis $\left(\mathrm{Abs} / 1 \times 10^{8}\right.$ cells $\left.=0.45 \pm 0.15\right)$ cells (Table 1). There were, however, some discrepancies when comparing the relative strain hierarchy for metabolic activity for the planktonic and biofilm cultures. A possible explanation for this relates to potential additional significant phenotypic differences occurring between the two lifestyles $[22,25]$. Perhaps the most important of these are those factors that relate to the promotion, persistence and virulence of the organisms within the host environment. As biofilm cells are organised into structured communities embedded within an extracellular matrix, activity within biofilms would be dependent on nutrient access and availability of oxygen, together with removal of waste products. These factors may vary because of inherent differences in the biofilms produced by the tested strains and species, with the resulting alteration in cellular and biofilm metabolic activity. Indeed, evidences of variation in biofilm spatial arrangement are possible observed in Fig. 3. For instances (Fig. 3b), concerning C. tropicalis 12, which possess high number of CFU (Fig. 2) and low activity (Fig. 1), it is possible to verify that its biofilm is more cohesive than C. tropicalis 75, which presents lower CFU number (Fig. 2) as well as metabolic activity (Fig. 1). The same was observed for C. glabrata (Fig. 3a) and C. parapsilosis (Fig. 3c) biofilms. Thus, an effect on the ability of XTT to diffuse into these 'different' biofilms is an aspect that also cannot be disregarded. When total biofilm activity was normalised against $1 \times 10^{8} \mathrm{CFU}$ of resuspended biofilm (Table 1), it was evident that the relative biofilm activity of C. glabrata was 100 times less than $C$. tropicalis and 10 times lower than $C$. parapsilosis. Interestingly, this analysis highlights additional heterogeneity in terms of relative biofilm metabolic activity between $C$. parapsilosis and $C$. tropicalis. Furthermore, the results indicate that, in general, biofilms formed by clinical isolates had a much lower relative activity compared to the corresponding reference strains, with the exception of $C$. parapsilosis ATCC 22019.

In summary, this study underlines both species and strain differences in biofilm metabolic activity which in 
Fig. 3 Biofilm scanning electron microscopy images of two C. glabrata $(\mathbf{a})$,

C. tropicalis $(\mathbf{b})$ and C. parapsilosis (c) strains formed in SDB for $48 \mathrm{~h}$. Magnification $3000 \times$, bar $10 \mu \mathrm{m}$
(A)
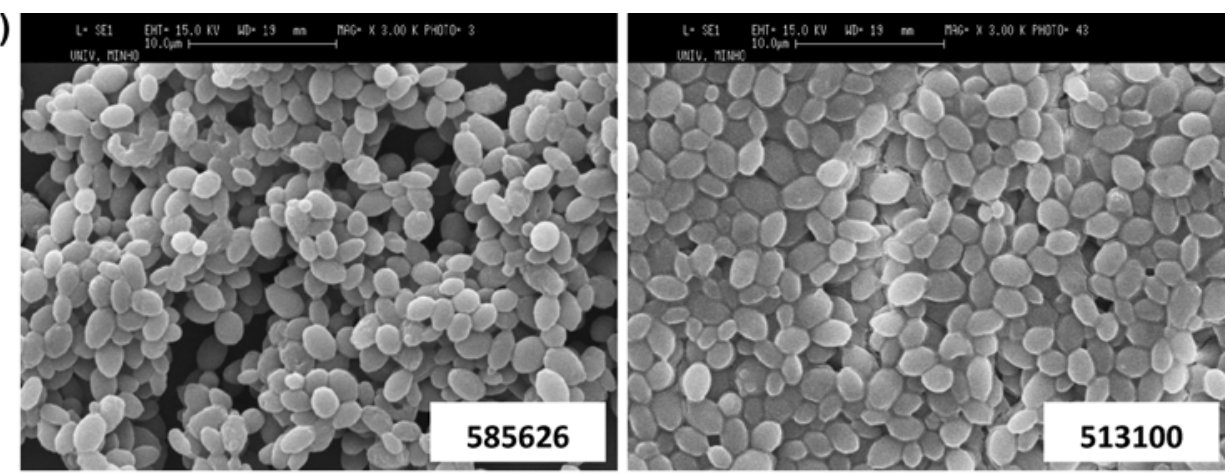

(B)
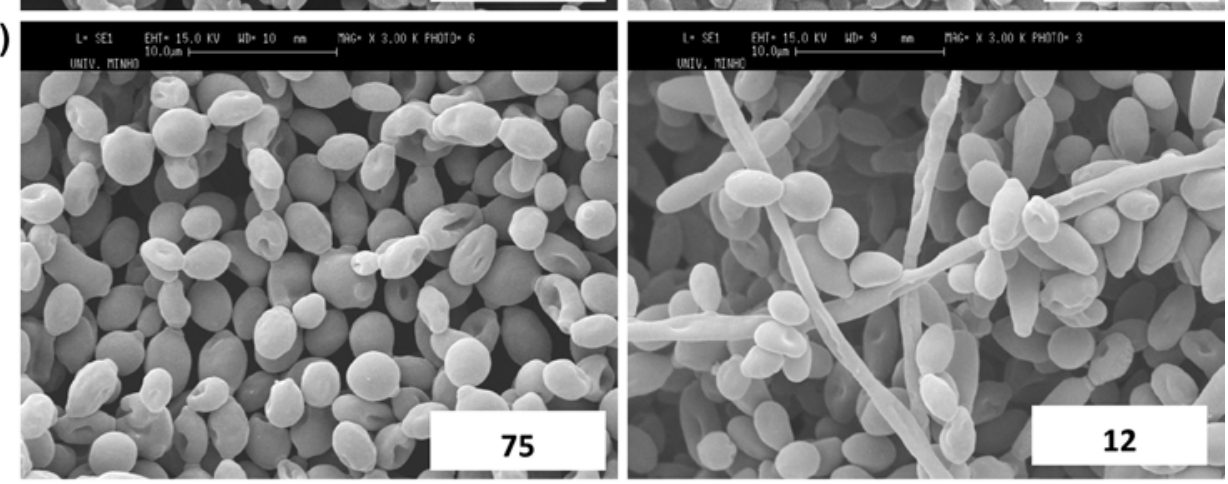

(C)
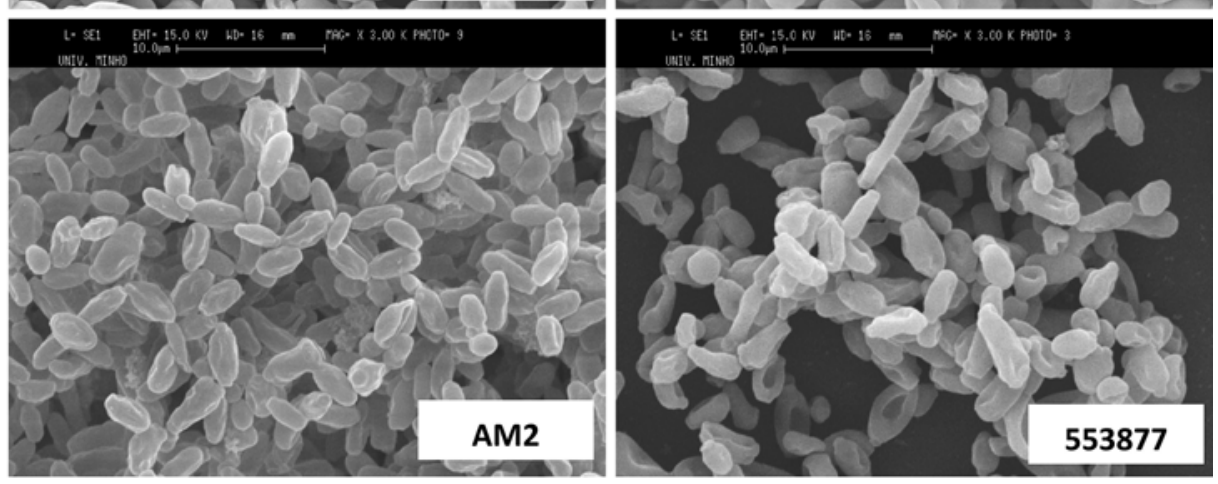

part reflects the inherent physiological differences between the organisms. However, it has also to be considered that intrinsic biofilm factors may have a direct effect on the responses obtained. These findings may have significance concerning the pathogenic potential of the strains tested when extrapolated to in vivo situations, with the clinical isolates generally having a lower activity than the equivalent reference species. Such a relatively low activity could promote persistence of the isolates within a clinical environment once the biofilm has become established. Another important aspect raised by this study is that future research needs to consider which is the most appropriate parameter to investigate in vitro biofilm models since total biofilm activity or cultivable cells number do not necessarily reflect the behaviour of the biofilm itself.

Acknowledgements The authors acknowledge 'Fundação para a Ciência e Tecnologia (FCT), Portugal, for supporting Sonia Silva's study through grant SFRH/BD/28341/2006 and project PDTC/BIO/
61112/2004. The authors are also grateful to Hospital de S Marcos, Braga for providing the clinical isolates.

\section{References}

1. Al-Fattani MA, Douglas LJ (2006) Biofilm matrix of Candida albicans and Candida tropicalis: chemical composition and role in drug resistance. J Med Microbiol 55:999-1008

2. Baillie GS, Douglas LJ (1999) Role of dimorphism in the development of Candida albicans biofilm. J Med Microbiol 48:671-679

3. Baillie GS, Douglas LJ (2000) Matrix polymers of Candida biofilms and their possible role in biofilm resistance to antifungal agents. J Antimicrob Chemother 46:397-403

4. Bassetti M, Righi E, Costa A et al (2006) Epidemiological trends in nosocomial candidemia in intensive care. BMC Infect Dis 6:21

5. Chandra J, Kuhn DM, Mukherjee PK et al (2001) Biofilm formation by the fungal pathogen Candida albicans: development, architecture and drug resistance. J Bacteriol 183:5385-5394

6. Colombo AL, Perfect J, DiNubile M et al (2003) Global distribution and outcomes for Candida species causing invasive 
candidiasis: results from an international randomized doubleblind study of caspofungin versus amphotericin B for the treatment of invasive candidiasis. Eur J Microbiol Infect Dis 22: $470-474$

7. Costerton JW, Lewandowski Z, Caldwell DE et al (1995) Microbial biofilms. Annu Rev Microbial 49:711-745

8. Douglas LJ (2003) Candida biofilms and their role in infection. Trends Microbiol 11:30-36

9. Fidel PL, Vazquez JA, Sobel JD (1999) Candida glabrata: review of epidemiology, pathogenesis, and clinical disease with comparison to C. albicans. Clin Microbiol Rev 12:80-96

10. Hargety JA, Ortiz J, Reich D et al (2003) Fungal infections in solid organ transplant patients. Surg Infect (Larchmt) 4:263-271

11. Hasan F, Xess I, Wang X et al (2009) Biofilm formation in clinical Candida isolates and its association with virulence. Microbes Infect 11:753-761

12. Hawser SP, Douglas LJ (1994) Biofilm formation by Candida species on the surface of catheter materials in vitro. Infect Immun 62:915-921

13. Hawser SP (1996) Comparisons of the susceptibility of planktonic and adherent Candida albicans to antifungal agents: a modified XTT tetrazolium assay using synchronized $C$. albicans cells. J Med Vet Mycol 34:149-152

14. Hawser SP (1998) Production of extracellular matrix by Candida albicans biofilms. J Med Microbiol 47:253-256

15. Henriques M, Azeredo J, Oliveira R (2006) Candida albicans and Candida dubliniensis: comparison of biofilm formation in terms of biomass and activity. Brit J Biomed Sci 63:5-11

16. Jin Y, Yip KH, Samaranayake YH et al (2003) Biofilm-forming ability of Candida albicans is unlikely to contribute to high levels of oral yeast carriage in cases of human immunodeficiency virus infection. J Clin Microbiol 41:2961-2967

17. Kiehn TE, Edwards FF, Armstrong D (1980) The prevalence of yeasts in clinical specimens from cancer patients. Am J Clin Pathol 73:518-521

18. Kuhn DM, Chandra J, Mukherjee PK et al (2002) Comparison of biofilms formed by Candida albicans and Candida parapsilosis on bioprosthetic surfaces. Infect Immunol 70:878-888
19. Kuhn DM, Balkis M, Chandra J et al (2003) Uses and limitations of the XTT assay in studies of Candida growth and metabolism. $\mathrm{J}$ Clin Microbiol 41:506-508

20. Kwon-Chung KJ, Bennett JE (1992) Dermatophytoses. In: Medical mycology, 1st edn. Lea \& Febiger, Pennsylvania, pp. 105-161

21. Mah TFC, Toole GAO (2001) Mechanisms of biofilm resistance to antimicrobial agents. Trends Microbiol 9:34-39

22. Mukherjee PK, Chandra J, Kuhn DM et al (2003) Mechanism of fluconazole resistance in Candida albicans biofilms: phase-specific role of efflux pumps and membrane sterols. Infect Immun 71:4333-4340

23. Odds FC (1994) Pathogenesis of Candida infections. J Am Acad Dermatol 31:2-5

24. Odds FC (1998) Candida and candidosis, 2nd edn. Bailliere Tindall, London

25. Ramage G, Saville PS, Thomas PD et al (2005) Candida biofilms: an update. Eukaryot Cell 4:633-638

26. Samaranayake LP (1990) Host factors and oral candidosis. In: Oral candidosis. Butterworth \&Co (Publishers), London, pp 66103

27. Samaranayake LP, Fidel PL, Naglik JR et al (2002) Fungal infections associated with HIV infection. Oral Dis 8:151-160

28. Shin JH, Kee SJ, Shin MG et al (2002) Biofilm production by isolates of Candida species recovered from nonneutropenic patients: comparison of bloodstream isolates with isolates from other sources. J Clin Microbiol 40:1244-1248

29. Williams DW, Wilson MJ, Lewis MAO et al (1995) Identification of Candida species by PCR and restriction fragment length polymorphism analysis of intergenic spacer regions of ribosomal DNA. J Clin Microbiol 33:2476-2479

30. Zaw MT, Samaranayake YH, Samaranayake LP (2007) In vitro biofilm formation of Candida albicans and non-albicans Candida species under dynamic and anaerobic conditions. Arch Oral Biol 52:761-767 